\title{
Taalabstractie in communicatie over producten: wanneer beschrijven we een ervaring met een product concreet en wanneer abstract?
}

Dit artikel laat zien dat er in mond-tot-mondreclame over producten een systematische vertekening optreedt in het taalgebruik. Net als in eerder onderzoek naar taalabstractie in beschrijvingen van interpersoonlijk gedrag, gebruiken mensen bij het beschrijven van productervaringen meer abstracte taal wanneer de ervaring overeenkomt met de verwachting die men vooraf heeft.

\section{Introductie}

In het dagelijks leven praten mensen regelmatig over hun ervaringen met producten en diensten. Deze conversaties staan ook wel bekend als mond-tot-mondreclame, waarbij opgemerkt dient te worden dat het hierbij - ondanks het gebruik van de term reclame - gaat om zowel positieve als negatieve conversaties over de producten en diensten. Mond-tot-mondreclame is een van de oudste en meest invloedrijke methoden om informatie over diensten en producten te verspreiden en te vergaren en heeft sinds het invloedrijke werk van Katz en Lazarsfeld (I955) doorlopend aandacht gekregen van onderzoekers (Arndt, I967; Brown \& Reingen, I987; Chevalier \& Mayzlin, 2006). Binnen onderzoek naar mond-tot-mondreclame is er veel aandacht voor de vraag wie deze informatie verspreidt en waarom, en naar de invloed van de communicatie op ontvangers, en factoren die deze invloed vergroten of verkleinen. Er is echter weinig onderzoek gedaan naar de vraag wat er verteld wordt en hoe. Met name het hoe wordt in dit artikel nader bestudeerd.

* Gaby Schellekens is universitair docent Bedrijfscommunicatie aan de Radboud Universiteit Nijmegen. Contactgegevens: Erasmusplein I (Kamer E05.26), 6525 HT Nijmegen. E-mail: g.schellekens@let.ru.nl, tel: + 3I 24 36I 2365, fax: + 3I 24 36I 2I 77.

Peeter Verlegh is werkzaam als associate professor aan de Amsterdam School of Communication Research, Universiteit van Amsterdam.

Ale Smidts is werkzaam als professor of marketing research aan de Rotterdam School of Management, Erasmus University. 
Er zijn verschillende manieren waarop consumenten hun ervaringen en beoordelingen van producten en diensten kunnen verwoorden. Zo kan iemand een negatieve ervaring met een T-shirt dat na één keer wassen zijn kleur verliest, beschrijven als 'mijn shirt is verkleurd', maar deze persoon kan ook zeggen 'mijn shirt is van slechte kwaliteit'. In het eerste geval geeft de persoon een concrete beschrijving van de ervaring, en in het laatste geval een abstracte verwoording, die de ervaring generaliseert van een specifieke gebeurtenis naar een meer algemene indruk van de kwaliteit van het T-shirt.

Taalabstractie is een belangrijk kenmerk van taalgebruik, en is met name binnen de sociale psychologie veel bestudeerd. Door de abstractheid van taal te variëren, kunnen mensen eenzelfde gebeurtenis beschrijven op uiteenlopende manieren. De (veelal onbewuste) keuzes die daarbij gemaakt worden, geven informatie over de afzender en zijn of haar ideeën en bedoelingen (Semin \& Fiedler, I988, I989; Maass, Milesi, Zabbini \& Stahlberg, I995). Taalabstractie kan ook een belangrijke rol spelen in het verwerken van informatie (Semin, 2000; Holtgraves \& Kashima, 2008; Wigboldus, Semin \& Spears, 2000), omdat het, onafhankelijk van de inhoud van de boodschap, de aandacht van een ontvanger kan vestigen op bepaalde facetten van het besproken onderwerp, zoals beschreven wordt in de volgende paragraaf.

\section{Linguïstisch categorieënmodel}

Bij het bestuderen van taalabstractie wordt veelal gebruik gemaakt van het linguïstisch categorieënmodel (Semin \& Fiedler, I988). Dit model onderscheidt vier niveaus van abstractie, die lopen van concreet (descriptieve actiewerkwoorden; DAW) via tussenliggende niveaus (interpretatieve actiewerkwoorden: IAW en toestandswerkwoorden; TW) naar abstract (adjectieven; Adj). Voorbeelden van deze vier niveaus zijn: 'Jan slaat Kees' (DAW), 'Jan pijnigt Kees' (IAW), 'Jan haat Kees' (TW) en 'Jan is agressief' (Adj). Het is van belang op te merken dat het bij taalabstractie volgens het linguïstische categorieënmodel draait om de manier waarop de informatie beschreven wordt. Hierbij wordt uitsluitend gekeken naar de werkwoorden en eventueel bijvoeglijke naamwoorden die gebruikt worden om een gedraging te omschrijven.

Volgens het model van Semin en Fiedler (I988) wekt een meer abstracte beschrijving van gedrag de indruk dat de gebeurtenis veroorzaakt wordt door een typische en stabiele karaktereigenschap van de handelende persoon, terwijl een meer concrete beschrijving de aandacht richt op de specifieke situatie waarin het gedrag plaatsvindt (Semin \& Fiedler, I988). Een concrete beschrijving focust dus op een eenmalige gebeurtenis in een specifieke context en verwijst naar zintuiglijk waarneembare zaken, terwijl een abstracte omschrijving de gebeurtenis generaliseert tot een persoonlijke eigenschap (Douma, I994). In dit artikel willen wij laten zien dat taalabstractie een belangrijk aspect is van mond-tot-mondcommunicatie, en dat het linguïstisch categorieënmodel een bruikbaar raamwerk biedt voor de bestu- 
dering ervan. Voor een meer uitgebreide beschrijving van het linguïstisch categorieënmodel verwijzen wij naar de achterliggende publicaties van Semin en Fiedler (ı)88, ig89; Semin, 2000).

\section{Linguïstische verwachtingsvertekening en linguïstische tussengroepsvertekening}

Eerder onderzoek in de sociale psychologie heeft aangetoond dat de taalabstractie die mensen gebruiken om het gedrag van anderen te beschrijven, wordt beïnvloed door de mate waarin dit gedrag overeenkomt met hun verwachtingen (Maass, Salvi, Arcuri \& Semin, I989; Maass et al., I995; Webster, Kruglanski \& Dwight I997; Wigboldus, Spears \& Semin, 2000). Deze verwachtingen kunnen bijvoorbeeld gebaseerd zijn op stereotypen of op groepslidmaatschap. Wanneer men op basis van groepslidmaatschap bijvoorbeeld verwacht dat iemand bepaald gedrag vertoont, wordt er abstracte taal gebruikt voor beschrijvingen van gedrag dat overeenkomt met deze verwachting (bijvoorbeeld 'de skinhead is agressief of 'de vrouw is zorgzaam'), en concrete taal wanneer het gedrag afwijkt van de verwachting (bijvoorbeeld 'de skinhead brengt zijn kinderen naar school' of 'de vrouw slaat iemand'). Ditzelfde geldt bijvoorbeeld voor gedrag van ploeggenoten en tegenstanders in sportwedstrijden ('mijn teamgenoot is behulpzaam' versus 'de tegenstander helpt iemand opstaan' en 'mijn medespeler duwt een tegenstander opzij' versus 'de tegenstander is onsportief'). Deze stelselmatige vertekeningen staan bekend als de 'linguïstische verwachtingsvertekening' ( Iinguïstic expectancy bias') en de 'linguïstische tussengroepsvertekening' ('inguïstic intergroup bias').

Eerder onderzoek heeft laten zien dat mensen zich niet bewust zijn van het niveau van taalabstractie in hun communicatie, of van factoren die dit zouden kunnen beïnvloeden (Maass et al., I995; Franco \& Maass, I996; Webster et al., I997). Daarnaast is aangetoond dat de effecten van taalabstractie niet verklaard kunnen worden door verschillen in positiviteit of negativiteit van beschrijvingen (Schellekens, Verlegh \& Smidts, 20I0). Sociaalpsychologisch onderzoek naar taalabstractie beperkt zich echter grotendeels tot communicatie over tussengroepsgedrag, terwijl mensen ook frequent communiceren over gebruiksvoorwerpen en producten (mond-tot-mondreclame). Er is slechts één eerder artikel dat onderzoek deed naar de rol van taalabstractie in mond-tot-mondreclame (Schellekens, Verlegh \& Smidts, 20I0). Dit eerdere onderzoek richtte zich met name op de effecten van taalabstractie op de ontvanger. Het gebruik van taalabstractie voor het beschrijven van positieve en negatieve ervaringen werd slechts onderzocht voor twee verschillende producten. Het huidige onderzoek vormt een substantiële uitbreiding van het onderzoek naar de rol van taalabstractie in mond-tot-mondcommunicatie, door zich te richten op vier verschillende producten. Daarnaast heeft het artikel tot doel het linguïstisch categorieënmodel onder de aandacht te brengen van communicatiewetenschappers. Een literatuuronderzoek wees uit dat het model tot op heden in slechts drie wetenschappelijke artikelen binnen de communicatiewetenschap is toegepast (Fiedler, 
Semin \& Finkenauer, I993; Gorham, 2006; Schmid \& Fiedler, I996). Elk van deze publicaties richtte zich op het bestuderen van taalgebruik bij de beschrijving van bepaalde groepen. Twee studies gingen over het taalgebruik bij het beschrijven van misdaden (Gorham, 2006; Schmid \& Fiedler, I996), en één studie ging over taalgebruik in beschrijvingen van mannelijk versus vrouwelijk gedrag (Fiedler, Semin \& Finkenauer, I993). Door te laten zien dat het model ook kan worden gebruikt bij de bestudering van taalgebruik in beschrijvingen van alledaagse ervaringen met producten, hopen wij te bereiken dat ook communicatiewetenschappers zich zullen richten op de studie van taalabstractie, om vanuit hun specifieke expertise de kennis over dit onderwerp te verrijken.

\section{Taalabstractie in communicatie over objecten en producten}

Het huidige onderzoek richt zich zoals gezegd op communicatie over ervaringen met objecten en producten. Onder deze ervaringen vallen bijvoorbeeld enthousiaste verhalen over de veelzijdigheid van een nieuwe mobiele telefoon, of over een spannend boek, maar ook klaagzangen over een kapotte auto of trage computer. Wij bekijken of dergelijke ervaringen worden beschreven in meer abstracte termen wanneer zij congruent (in plaats van incongruent) zijn met de verwachtingen van de waarnemer. Deze hypothese is niet vanzelfsprekend. In beschrijvingen van interpersoonlijk gedrag suggereert meer abstracte taal dat de beschrijver aan wil geven dat het beschreven gedrag een persoonseigenschap of karaktertrek weerspiegelt (Semin \& Fiedler, I988; Wigboldus, et al., 2000). Er wordt daarbij impliciet verondersteld dat een persoon vrij is om te handelen en ervoor kan kiezen om zich op een bepaalde manier zich te gedragen, verschillend van situatie tot situatie. Wanneer een waarnemer verwacht dat de persoon in verschillende situaties op eenzelfde manier zal handelen, dan zal deze waarnemer het gedrag toeschrijven aan het karakter van de persoon (Semin \& Fiedler, I988). Gebruiksvoorwerpen kunnen er echter niet voor kiezen om zich anders te gedragen in verschillende situaties, waardoor het niet vanzelfsprekend is dat er een systematische variatie zal optreden in de taalabstractie van beschrijvingen van gebruikservaringen met het voorwerp. Dit werd ook opgemerkt door Wigboldus en Douglas (2007), die oproepen tot meer onderzoek naar taalabstractie in beschrijvingen van objecten.

In dit artikel onderzoeken we daarom of gebruikers van producten meer abstracte beschrijvingen geven voor ervaringen die overeenstemmen met hun verwachting, dan voor ervaringen die afwijken van hun verwachting. In lijn met eerder onderzoek verwachten wij dat een ervaring die congruent is met de verwachting van de gebruiker eerder zal worden beschouwd als typisch en representatief, en voortvloeiend uit de kenmerken of kwaliteiten van het product zelf. Minder waarschijnlijk is dat de ervaring wordt toegeschreven aan de situatie waarin het product werd gebruikt, of aan de gebruiker. Verwachtingscongruente ervaringen (bijvoorbeeld een positieve ervaring met een product van je favoriete merk), zullen daardoor eerder 
abstract beschreven worden, omdat abstract taalgebruik de ervaring weergeeft als een stabiele eigenschap van het product. Daarentegen zullen mensen een incongruente ervaring (bijvoorbeeld een negatieve ervaring met een product van je favoriete merk), eerder beschouwen als een uitzondering op de regel. Zij zullen waarschijnlijk meer terughoudend zijn om de ervaring toe te schrijven aan de eigenschappen van het product en ervoor kiezen om de ervaring te beschrijven in concrete termen.

Om dit idee te verduidelijken, bekijken we een voorbeeld van vier beschrijvingen van een productervaring corresponderend met de niveaus van taalabstractie volgens het linguïstisch categorieënmodel. Dit voorbeeld is daadwerkelijk gebruikt in het huidige onderzoek. Wanneer bijvoorbeeld een mp3-speler van het fictieve merk 'Trevor' een mp3-bestand goed afspeelt, kan dit volgens het linguïstisch categorieënmodel oplopend van concreet naar abstract worden beschreven als:

I. 'De Trevor speelt de mp3 [niet] goed af' (descriptieve actiewerkwoorden)

2. 'De Trevor werkt [niet] goed' (interpretatieve actiewerkwoorden)

3. 'De Trevor bevalt de studente [niet]' (toestandswerkwoorden)

4. 'De Trevor is een goed [slecht] product' (adjectieven)

Onze hypothese is dat positieve productervaringen beschreven worden op meer abstracte wijze door personen met een positieve verwachting ten aanzien van het product, dan door personen met een negatieve verwachting ten aanzien van het product. Voor negatieve productervaringen verwachten wij dat zij juist op meer concrete wijze worden beschreven door personen met positieve verwachting dan door mensen met een negatieve verwachting.

\section{Methode}

\section{Proefpersonen en onderzoeksontwerp}

I44 studenten $(52 \%$ mannen; gemiddelde leeftijd $=2 \mathrm{I} . \mathrm{I} 9$ jaar $(S D=2.7 \mathrm{I}))$ werden willekeurig toegewezen aan een gebalanceerd 2 (verwachting van producten: positief vs. negatief) x 2 (ervaring met product: positief vs. negatief) $\times 4$ (product: telecommunicatienetwerk, yoghurt, T-shirt en mp3-speler)-ontwerp, waarbij de eerste twee variabelen tussen-proefpersonen gevarieerd zijn, en de laatste variabele binnen-proefpersonen. Voor elk product werden de proefpersonen blootgesteld aan een andere combinatie tussen de verwachting en de productervaring. Dus de proefpersonen doorliepen de vier combinaties van het tussen-proefpersoonontwerp voor alle vier de producten (aangeboden in willekeurige volgorde).

\section{Procedure}

Verwachting werd gemanipuleerd door een korte productbeschrijving. Om de manipulatie van een verwachting over een product te vergemakkelijken, werden er fictieve productnamen gebruikt. De productbeschrijving voor de positieve verwachting 
was bijvoorbeeld: 'Stel je voor dat je zeer positief bent over Trevor mp3-spelers. Je bent wel eens in het bezit geweest van een Trevor mp3-speler en was er zeer tevreden over'. In de negatieve beschrijving was 'positief vervangen door 'negatief en 'tevreden' door 'ontevreden'.

Daarna kregen de proefpersonen een positieve (vs. negatieve) filmclip van een productervaring te zien van ongeveer 5-10 seconden. De film van de mp3-speler toonde bijvoorbeeld een persoon (studente) die vrolijk zat te luisteren naar haar mp3-speler (positieve ervaring) of die er gefrustreerd uitzag door de slechte geluidskwaliteit van haar mp3-speler (negatieve ervaring). Het gebruik van filmmateriaal stelde ons in staat om op praktische wijze een realistische ervaring aan te bieden die voor elke proefpersoon gelijk was. Het aanbieden van daadwerkelijke productervaringen met vier verschillende producten zou ten eerste zeer bewerkelijk zijn, en ten tweede veel moeilijker controleerbaar.

\section{Afhankelijke variabele}

De proefpersonen werd vervolgens gevraagd hoe ze de ervaring met het product tegen een andere student zouden vertellen. Zoals in eerder onderzoek (Douglas \& Sutton, 2003; Franco \& Maass, I996; Maass et al., I989) werden vier beschrijvingen van de positieve (vs. negatieve) ervaring voorgelegd volgens de vier niveaus van het linguïstisch categorieënmodel (DAW, IAW, TW en Adj). Dergelijke gesloten antwoordcategorieën hebben als voordeel dat de resultaten eenduidiger zijn, omdat het niet nodig is om het taalgebruik van respondenten te coderen voor taalabstractie. Eerder onderzoek heeft aangetoond dat de resultaten verkregen met deze methode niet systematisch verschillen van resultaten die verkregen zijn in studies waarin respondenten een ervaring konden beschrijven in hun eigen woorden en deze beschrijvingen vervolgens werd gecodeerd voor de abstractheid van het taalgebruik (Wigboldus et al., 2000; Schellekens et al., 20I0). Proefpersonen in de huidige studie werd gevraagd de beschrijving te kiezen die zij zouden gebruiken wanneer zij de productervaring met iemand anders zouden delen. In de analyses werden de vier niveaus (oplopend van concreet naar abstract) gecodeerd van I tot 4 en evenals in eerder LCM-onderzoek geanalyseerd als intervalschaal (Douglas \& Sutton, 2003; Maass, et al., I989).

Vervolgens werden de proefpersonen middels enkele open vragen gevraagd naar hun vermoedens over de hypotheses en doel van het experiment en hun taalkeuzes tijdens het onderzoek. Geen van de proefpersonen bleek kennis te hebben over deze zaken.

\section{Resultaten}

De data werd geanalyseerd middels een herhaalde metingenvariantieanalyse met productverwachting (positief vs. negatief) en ervaring met product (positief vs. negatief) als tussen-proefpersoonvariabelen. Als binnen-proefpersoonvariabele werd een 
product $\mathrm{x}$ verwachting/ervaring combinatievariabele toegevoegd: om het ontwerp overzichtelijk te houden werden er in het onderzoek in totaal acht verschillende combinaties van product en ervaring gebruikt, zodat elke persoon elke productclip eenmaal te zien kreeg, en steeds twee positieve en twee negatieve ervaringen zag. Deze laatste variabele had geen significant effect op taalabstractie $(F(\mathrm{I}, \mathrm{I} 42)=0.07$, $p=.79)$. De interactie-effecten met deze variabele waren evenmin significant $(F(\mathrm{I}, \mathrm{I} 42)<\mathrm{I} .72, \mathrm{p}>. \mathrm{I} 9)$. De hoofdeffecten van verwachting $(F(\mathrm{I}, \mathrm{I} 42)=\mathrm{I} .42$, $p=.24)$. en ervaring $(F(\mathrm{I}, \mathrm{I} 42)=\mathrm{I} .85, p=. \mathrm{I} 8)$ waren evenmin significant.

Het enige significante effect in deze analyse was het verwachting $\mathrm{x}$ ervaring interactie-effect $(F(\mathrm{I}, \mathrm{I} 42)=\mathrm{I5} .80, p<.00 \mathrm{I}$; eta-kwadraat $=0.10)$. Zoals verwacht werden ervaringen die congruent waren aan de verwachtingen van de proefpersonen $(M=3 . \mathrm{II} ; \mathrm{SD}=\mathrm{I} . \mathrm{I} 3)$ meer abstract gecommuniceerd dan incongruente ervaringen $(M=$ I.9I; $\mathrm{SD}=0.96)$. In lijn met onze voorspelling lieten contrastanalyses zien dat de positieve productervaringen meer abstract beschreven werd door personen met een positieve (vs. negatieve) verwachting $(F(\mathrm{I}, \mathrm{I} 42)=8.06, p<. \mathrm{oI}$; eta-kwadraat $=0.05)$. De negatieve ervaringen werden meer concreet beschreven door proefpersonen met een positieve (vs. negatieve) verwachting $(F(\mathrm{I}, \mathrm{I} 42)=\mathrm{I} 3 . \mathrm{IO}, p<.00 \mathrm{I}$; etakwadraat $=0.08$ ), zie figuur $\mathrm{I}^{2}$

Om te controleren voor een mogelijke invloed van geslacht op de uitkomsten werden bovenstaande analyses herhaald met 'geslacht' toegevoegd als tussen-proefpersoonfactor. Deze analyses wezen uit dat er geen significant hoofdeffect van geslacht op taalbastractie was $(\mathrm{F}(\mathrm{I}, \mathrm{I} 4 \mathrm{I})=0.04, \mathrm{p}=.85)$. De interactie-effecten met geslacht waren evenmin significant $(\mathrm{F}(\mathrm{I}, \mathrm{I} 4 \mathrm{I})<\mathrm{I} .87, \mathrm{p}>$.I7)

\section{Discussie}

Dit artikel laat zien hoe de taalabstractie van een beschrijving van een voorwerp wordt bepaald door de mate waarin een ervaring met een voorwerp in overeenstemming is met de verwachtingen van mensen. Proefpersonen beschreven een positieve ervaring met een product (bijv. muziek luisteren op een mp3-speler) abstracter wanneer zij een positievere verwachting hadden ten aanzien van dit product. Bij een positieve verwachting worden positieve ervaringen gezien als typisch en representatief voor het product. Abstract taalgebruik benadrukt dit. Wanneer proefpersonen een negatieve verwachting hadden, beschreven zij een positieve ervaring echter concreter. Concreet taalgebruik helpt deze ervaring te omschrijven als eenmalig en afwijkend van de norm.

Tegenovergestelde resultaten werden verkregen voor negatieve ervaringen; deze ervaringen worden meer abstract beschreven door proefpersonen met een negatieve (vergeleken met positieve) productverwachting. Samengevat, ervaringen die congruent zijn met de verwachtingen van de proefpersonen worden meer abstract gecommuniceerd dan ervaringen die incongruent zijn met verwachtingen. Geconcludeerd kan worden dat taalgebruik in communicatie over voorwerpen wordt verte- 


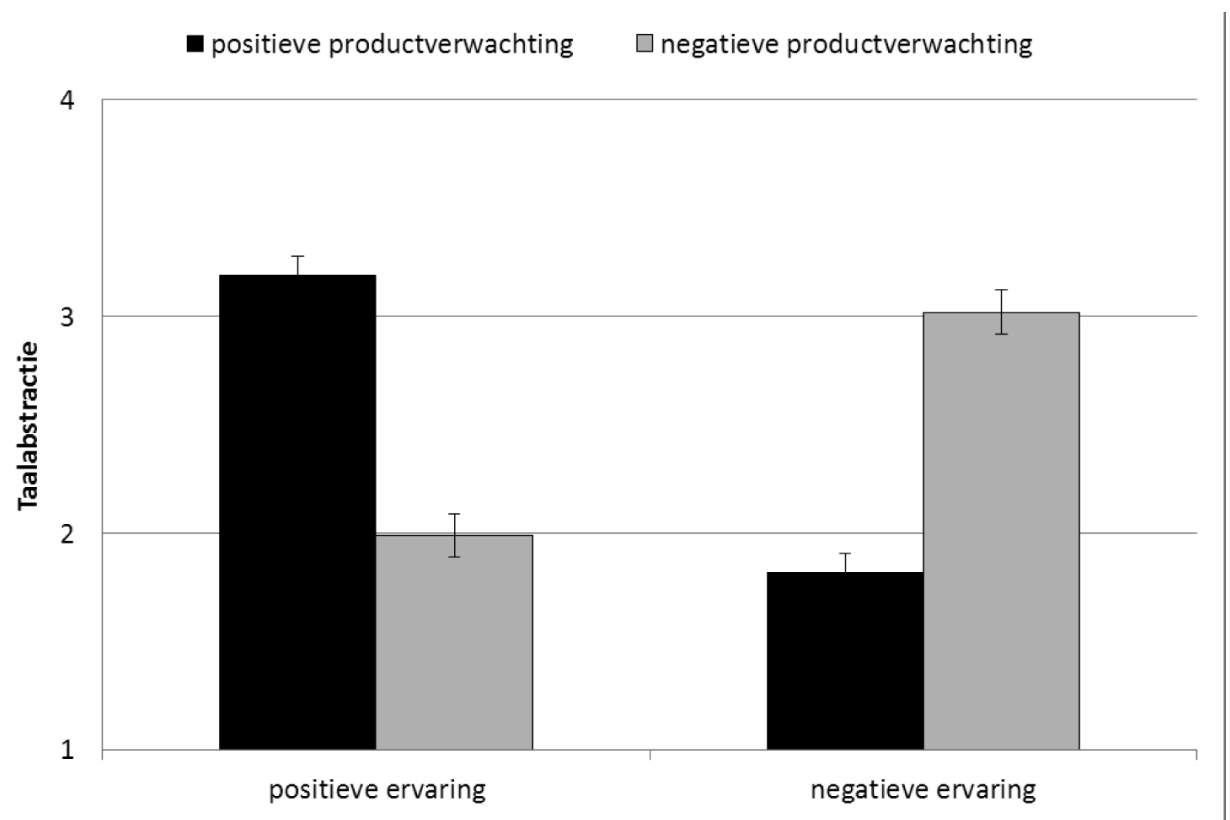

FIGUUR 1: Invloed van productverwachting en productervaring op het gebruik van taalabstractie

kend door de verwachtingen van degene die de ervaring met het voorwerp beschrijft.

Deze bevindingen kunnen gebruikt worden om meer inzicht te krijgen in het fenomeen van mond-tot-mondcommunicatie. Bedrijven proberen (voornamelijk online) mond-tot-mondreclame te analyseren, om meer te weten te komen over de meningen en wensen van consumenten. Het onderscheiden van concreet en abstract taalgebruik zou verdieping kunnen aanbrengen in deze analyses en wetenschappers en bedrijven kunnen helpen om hun consumenten beter te begrijpen (zie Godes \& Mayzlin, 2004; Liu, 2006). Door het analyseren van de taalabstractie in de productbeschrijvingen van consumenten wordt immers informatie verkregen over de onderliggende verwachtingen die consumenten (of in dit geval, de schrijvers van reviews) hebben ten aanzien van een product. Op deze wijze kan onderscheid gemaakt worden tussen consumenten die een negatieve ervaring als een eenmalige, uitzonderlijke gebeurtenis beschouwen en consumenten die deze ervaring zien als een bevestiging van hun negatieve verwachtingen. Zo kan men uit een concreet beschreven ongunstige review afleiden dat de zender over het algemeen positief is over het product of merk. Medewerkers van de klantenservice, of webcare teams zouden bijvoorbeeld extra aandacht kunnen schenken aan klanten die in concrete taal klagen, omdat er bij deze klanten een grote kans is dat zij na een effectieve klachtenafhandeling weer tevreden zijn.

Een beperking van het huidige onderzoek is dat er geen aandacht wordt besteed aan de rol van non-verbale communicatie. De wijze waarop een productervaring 
gecommuniceerd wordt kan veel informatie prijsgeven over de mening van de zender over een product. Toonhoogte, lichaamshouding en gelaatsuitdrukkingen kunnen bijvoorbeeld aanduiden dat een persoon overdrijft of juist terughoudend is in zijn of haar bewoordingen. Het zou dan ook interessant zijn om in toekomstig onderzoek meer aandacht te besteden aan de rol van non-verbale signalen in mondtot-mondreclame, temeer omdat dit onderwerp (net als de rol van taalabstractie in deze context) tot op heden weinig aandacht heeft gekregen in wetenschappelijk onderzoek, hoewel recentelijk Fennis en Stel (20II) onderzoek deden naar de rol van non-verbaal gedrag in verkoopgesprekken.

Een tweede beperking van dit onderzoek is dat de proefpersonen strikt genomen niet een ervaring die zij zelf beleefden beschreven, maar een ervaring die door een ander beleefd werd, en die door de proefpersonen werd bekeken als videoclip. Deze methode is in overeenstemming met eerder onderzoek naar taalabstractie, waarin proefpersonen werd gevraagd om een gedrag te omschrijven dat was afgebeeld in een cartoon. Hoewel het moeilijk is om op basis van theorie een a priori verwachting te formuleren, is het mogelijk dat het omschrijven van andermans gedrag en ervaringen leidt tot een ander niveau van taalabstractie dan het omschrijven van eigen ervaringen en gedrag. Dit is dan ook een interessant onderwerp voor aanvullend onderzoek.

Verder onderzoek naar taalabstractie bij voorwerpen zou meer inzicht kunnen bieden in het onderliggende mechanisme van dit effect. Hoewel linguïstische verwachtings- en tussengroepsvertekening bekend zijn in de sociale psychologie (Maass, et al., I989, I995; Webster et al., I997), is er nog relatief weinig onderzoek gedaan naar het onderliggende mechanisme. Bij inter-groepsgedrag suggereert meer abstracte taal dat een bepaald gedrag voortkomt uit een stabiele karaktereigenschap van de persoon. De beschrijver verwacht dat de persoon in andere situaties gelijk zal handelen en dat het gedrag dus niet afhankelijk is van de omgeving maar van de handelende persoon. Een vergelijkbaar mechanisme zou op kunnen treden bij de zender van beschrijvingen van ervaringen met voorwerpen en producten. Dit zou onderzocht kunnen worden door vast te stellen of de interpretatie van de oorzaak van een ervaring met een voorwerp het taalgebruik in beschrijvingen van voorwerpen medieert.

Verder onderzoek naar taalabstractie is nodig om te bepalen hoe deze taaleigenschap zich verhoudt tot andere eigenschappen, zoals taalintensiteit. In dergelijk onderzoek zouden bijvoorbeeld variaties in taalabstractie gecombineerd kunnen worden met variaties in intensiteit, zoals het gebruik van versterkende of afzwakkende markeringen in beweringen over een product (zie Hornix, Pieper \& Schellens, 2008). Een mogelijke hypothese voor een dergelijk onderzoek zou kunnen zijn dat versterkende markeringen een grotere invloed hebben op de persuasiviteit van concrete claims dan van abstracte claims. Meer concrete claims zijn immers meer objectief, waardoor het gebruik van versterkende markeringen wellicht minder snel leidt tot een vermindering van de geloofwaardigheid van een claim. 
Daarnaast is het bij toekomstig onderzoek naar taalabstractie in mond-tot-mondreclame bijvoorbeeld interessant om te kijken naar andere factoren (naast verwachtingen), die bepalen of mensen abstractere of concretere taal gebruiken bij het beschrijven van positieve en negatieve ervaringen. Een voorbeelden van een dergelijke factor is de invloed van de ontvangers (het publiek) op de communicatie. Zo zou men onderzoek kunnen doen naar de rol van de relatie tussen zender en ontvanger, of de mogelijke invloed van de verwachtingen van de ontvanger op taalabstractie. Een ander voorbeeld van een factor die van invloed kan zijn op taalabstractie is het doel waarmee gecommuniceerd wordt. Er is een aantal motieven bekend voor mond-tot-mondreclame (Dichter, I966; Sundaram, Mitra \& Webster, I998). Consumenten willen bijvoorbeeld hun status verbeteren door te vertellen over hun mooie nieuwe auto, maar praten ook over producten om bijvoorbeeld iemand anders te helpen door een goed product aan te bevelen, of te waarschuwen voor een tegenvaller. Dergelijke motieven zouden van invloed kunnen zijn op taalabstractie: meer abstracte taal benadrukt immers de algemene en stabiele kwaliteiten van een product. Het is dan ook zeer wel mogelijk dat consumenten bijvoorbeeld meer abstracte omschrijvingen gebruiken wanneer zij proberen om anderen te overtuigen van de kwaliteit van een product. Een soortgelijke stelling zou tevens onderzocht kunnen worden door een analyse van het gebruik van abstracte taal in verkoopgesprekken of reclame.

\section{Literatuur}

Arndt, J. (1967). Word of mouth advertising and informal communication. In D.F. Cox, Risk taking and information handling in consumer behavior (pp. I88-239). Boston: Boston University Press.

Brown, J.J. \& Reingen, P.H. (1987). Social ties and word-of-mouth referral behavior. Journal of Consumer Research, 14, 350-362.

Chevalier, J.A. \& Mayzlin, D. (2006). The effect of word of mouth on sales: Online book reviews. Journal of Marketing Research, 43, 345-354.

Dichter, E. (I966). How word-of-mouth advertising works. Harvard Business Review, 44(6), I47-166.

Douglas, K.M. \& Sutton, R.M. (2003). Effects of communication goals and expectancies on language abstraction. Journal of Personality and Social Psychology, 84, 682-696.

Douma, P. (1994) Wees zo concreet mogelijk: Schrijfadviseurs over concreet en abstract taalgebruik. Tijdschrift voor Taalbeheersing, 16, I6-31.

Fennis, B.M. \& Stel, M. (20II). The pantomime of persuasion: fit between nonvebral communication and influence strategies. Journal of Experimental Social Psychology, 47, 806-810.

Fiedler, K., Semin, G.R. \& Finkenauer, C. (1993). The battle of words between gender groups: A language-based approach to intergroup processes. Human Communication Research, 19, 409-44I.

Franco, F.M. \& Maass, A. (1996). Implicit versus explicit strategies of out-group discrimination: The role of intentional control in biased language use and reward allocation. Journal of Language and Social Psychology, 15, 335-359.

Godes, D. \& Mayzlin, D. (2004). Using online conversations to study word-of-mouth communication. Marketing Science, 23, 545-560.

Gorham, B.W. (2006). News media's relationship with stereotyping: The linguistic intergroup bias in response to crime news. Journal of Communication, 56, 289-308. 
Holtgraves, T.M. \& Kashima, Y. (2008). Language, meaning, and social cognition. Personality and Social Psychology Review, 12, 73-94.

Hornikx, J., Pieper, M. \& Schellens, P.J. (2008). Versterkende, afzwakkende en numerieke markeringen in claims over cosmeticaproducten: maken ze claims overtuigender? Tijdschrift voor Communicatiewetenschap, 36, 3-I4.

Katz, E. \& Lazarsfeld, P.F. (I955). Personal influence: The part played by people in the flow of mass communication. New York: Free Press.

Liu, Y. (2006). Word of mouth for movies: Its dynamics and impact on box office revenue. Journal of Marketing, 70(3), 74-89.

Maass, A., Salvi, D., Arcuri, L. \& Semin, G. (I989). Language use in intergroup contexts - the linguistic intergroup bias. Journal of Personality and Social Psychology, 57, 98I-993.

Maass, A., Milesi, A., Zabbini, S. \& Stahlberg, D. (I995). Linguistic intergroup bias -Differential expectancies or in-group protection. Journal of Personality and Social Psychology, 68, II6-г26.

Schellekens, G.A.C., Verlegh, P.W.J. \& Smidts, A. (20I0). Language abstraction in word of mouth. Journal of Consumer Research, 37, 207-223.

Semin, G.R. (2000). Agenda 2000 - Communication: Language as an implementational device for cognition. European Journal of Social Psychology, 30, 595-6I2.

Semin, G.R. \& Fiedler, K. (I988). The cognitive functions of linguistic categories in describing personssocial cognition and language. Journal of Personality and Social Psychology, 54(4), 558-568.

Semin, G.R. \& Fiedler, K. (I989). Relocating attributional phenomena within a language-cognition interface - the case of actors and observers perspectives. European Journal of Social Psychology, 19, 49I-508.

Schmid, J. \& Fiedler, K. (I996). Language and implicit attributions in the Nuremberg trials analyzing prosecutors' and defense attorneys' closing speeches. Human Communication Research, 22, 37I-398.

Sundaram, D.S., Mitra, K. \& Webster, C. (I998). Word-of-mouth communications: A motivational analysis. Advances in Consumer Research, 25, 527-53I.

Webster, D.M., Kruglanski, A.W. \& Pattison, D.A. (I997). Motivated language use in intergroup contexts: need-for-closure effects on the linguistic intergroup bias. Journal of Personality and Social Psychology, 72, II22-II3I.

Wigboldus, D.H.J., \& Douglas, K.M. (2007). Language, Stereotypes, and Intergroup relations. In K. Fiedler (ed.), Social communication (pp. 79-Io6). NY and Hove: Psychology Press.

Wigboldus, D.H.J., Semin, G.R. \& Spears, R. (2000). How do we communicate stereotypes? Linguistic bases and inferential consequences. Journal of Personality and Social Psychology, 78, 5-18.

\section{Noten}

I De auteurs bedanken onderzoeksschool ERIM voor het ondersteunen en faciliteren van dit onderzoek.

2 In aanvulling op deze analyses is er een niet-parametrische analyse uitgevoerd waarbij het ordinale karakter van de data in ogenschouw is genomen: een Wilcoxon signed rank test wees uit dat ervaringen die congruent waren met de verwachting van de proefpersoon meer abstract werden beschreven dan ervaringen die incongruent waren $(\mathrm{Z}=8.46 ; \mathrm{p}<. .00 \mathrm{I})$. 